\title{
Study of Load Bearing Capacity of Profiled Steel Sheet Wall Subjected to Combined Bending and Vertical Compression in Electrostatic Precipitator
}

\author{
Dengfeng Wang ${ }^{*}, 1$, Yongfu $\mathrm{Yu}^{1}$, Licheng Pan ${ }^{1}$ and Haijin Dai ${ }^{2}$ \\ ${ }^{1}$ School of Environment and Civil Engineering, Jiangnan University, Wuxi 214122, P.R. China \\ ${ }^{2}$ Fujian Longking Co., Ltd, Longyan 364000, P.R. China
}

\begin{abstract}
For some electrostatic precipitators, profiled steel sheets are used as casing wall which is subjected to both bending and vertical compression. By nonlinear finite element method, the influences of structural parameters on load bearing capacity of profiled steel sheet wall were investigated. For the loading path, the uniform transversal pressure was applied firstly, and then the vertical compression was applied until the wall failed. The results indicate that the vertical compression resistance of profiled sheet decreases with the transversal load or the increasing sheet span. For certain sheet shape, the vertical compression resistance of profiled sheet decreases with the wall width increasing. The vertical resistance of the profiled sheet whose tensioned flanges are connected with the side columns is more than that whose compressed flanges are connected with the side columns. When the vertical compression resistance is calculated according to the buckling evaluation method of cold-form thin-walled steel member, the value is usually less than the solution from finite element method. Consequently, the load bearing capacity based on the related method of cold-form thin-walled steel member can be taken as a reference solution for the profiled steel sheet subjected to combined bending and vertical compression.
\end{abstract}

Keywords: Casing of electrostatic precipitator, Bending and vertical compression, Load bearing capacity, Nonlinear finite element method, Profiled steel sheet wall.

\section{INTRODUCTION}

The electrostatic precipitator is an important environmental protection equipment to eliminate dust. It is widely used in the industries of thermal power, metallurgy, chemical and building materials. The casing is the most important technical part of the electrostatic precipitator. Stiffened steel plate structure is generally used in the casing wall of traditional large scale electrostatic precipitator. For medium or small electrostatic precipitator projects, now profiled steel sheet is being explored to construct the casing wall. Profiled steel sheet is connected to the beams and columns by continuous welding. The structure of casing wall is shown in Fig. (1). When the profiled steel sheet is erected vertically, it is subjected to not only the pressure difference between the inside and outside of casing (called negative pressure) and wind load, but also the vertical compression acting on the top beam. Consequently, the profiled steel sheet bears the combined loads of both transversal uniform pressure and vertical compression.

For profiled steel sheet, Uy and Bradford studied the local buckling behavior of profiled trough girders in bending by the elastic finite strip method, and the profiled trough girders with three typical types of profiled steel sheeting

*Address correspondence to this author at the School of Environment and Civil Engineering, Jiangnan University, Wuxi 214122, P.R. China; Tel: 08615161597381; Fax: 086-0510-85910932; E-mail: happywdf@126.com configurations were compared [1]. For determining the flexural and membrane restraining effects of the sheet, Lucas et al. investigated the full model and simplified model for the structural system which consists of profiled steel sheet and purlin $[2,3]$. Akhand et al. conducted an experimental study on the behavior of re-entrant profiled sheet of lowductility steel under combined web crippling and flexure, and then, a nonlinear finite element model was proposed which can predict the moment-rotation characteristics of such sheeting with reasonable accuracy [4]. Alinia presented a procedure for modeling and analysis of shear panels containing central or edge cracks by the finite element method; besides, the influences of mesh refinements around the crack tips and edges and the relative crack length on buckling capacity and post buckling of shear panels were investigated [5]. A few researches were focused on the load bearing performance of profiled steel sheet in composite structures. The nature of profiled composite walls under combined axial and flexural loads and under in-plane loads was investigated $[6,7]$. For the investigation procedures, the experiments were conducted firstly; the numerical models which could successfully simulate the experiment results were set up sequentially; finally, the parametric study was undertaken. Mezzomo evaluated the best alternatives for trapezoidal-shaped cross-sections of profiled steel sheet used in roof cladding, considering pure bending and different boundary conditions. The analyses were carried out by using three-dimensional shell finite element models combined with optimization routines based on Genetic Algorithms [8]. 
Only the design method for profiled steel sheet subjected to bending moment has been provided in the current relevant specifications [9]. However, there are very few research results referring to pure profiled steel sheet bearing both bending and compression, even lacking a specification for guiding the design. According to the general geometry and load conditions of casing wall in electrostatic precipitators, by the method of nonlinear finite element, the investigation has been conducted for observation of the influences of configuration and load factors on the bearing capacity of the profiled steel sheet subjected to both bending and compression.

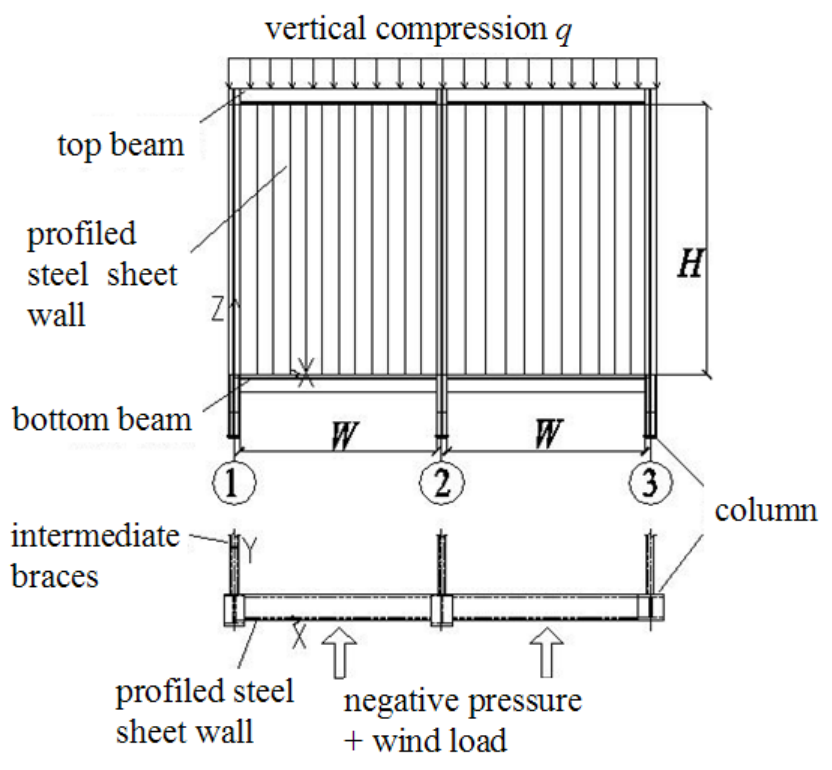

Fig. (1). Wall-column system of casing in electrostatic precipitator.

\section{ANALYSIS MODEL}

\subsection{Structural Model}

To simplify the computation model and improve computational efficiency, the computation model does not comprise of the entire casing. The structural unit for investigation is composed of two neighboring columns, the top beam, the bottom beam, and the profiled steel sheet wall that covers the area between the members. Beams and columns adopt rectangular tubular section. The width of the wall is $W$, and the height is $H$. The value of the transversal loads acting directly on casing wall is $P$ which is the sum of negative pressure and wind loads. The vertical uniform load is $q$, which acts on the top beams. Displacement coordinate system is shown in Fig. (1).

\subsection{Finite Element Model}

Finite element code package ANSYS is taken into account to conduct the analyses. The profiled steel sheet, beams and columns are all simulated by SHELL181 elements. The casing structure is made with Q235 steel, adopting ideal elastic-plastic material model with elastic modulus $E=2.06 \times 10^{5} \mathrm{MPa}$ and Poisson's ratio $v=0.3$. The yielding strength $f_{\mathrm{y}}$ is $235 \mathrm{MPa}$. For calculating geometrical nonlinearity, arc-length method is taken to trace the structural response path. Mesh accuracy test is conducted before setting up the finite element model, which could guarantee the satisfied computational accuracy.

\subsection{Loads and Constraints}

Taking the practical constraints into consideration, the $\mathrm{Y}$ direction translational constraints are applied to the inside of top and bottom beams. Translational constraints of three directions are applied to the column bases and the translational constraints of $\mathrm{Y}$ direction are applied to the top of columns. Besides, the translational constraints of $\mathrm{X}$ direction are applied to the edge columns.

According to the construction and operation process of electrostatic precipitator, negative pressure is applied in the commissioning stage, and the vertical load is applied in operation stage mainly including the dust load. Consequently, regarding the loading path, two load steps are applied to the finite element model. Firstly, the transversal uniform pressure $P$ is applied to the wall. Secondly, the vertical uniform pressure $q$ is applied onto the top beam until the structure fails.

\section{ANALYSIS OF PROFILED STEEL SHEET LOADING PROCESS}

The nonlinear analyses are conducted on the basis of the practical casing structure geometry and load cases. The typical cross section between a wave range of profiled steel sheet wall is shown in Fig. (2). The geometrical parameters of the cross section include: $\theta=45^{\circ}, t=3 \mathrm{~mm}, h=200 \mathrm{~mm}, b_{1}$ (width of compressed flange under transversal loads) $=100 \mathrm{~mm}, b_{2}$ (width of tensioned flange) $=200 \mathrm{~mm}$. The width $W$ of a block of wall comprising 4 waves is equal to $3 \mathrm{~m}$, and the wall height $H$ is equal to $2.5 \mathrm{~m}$.

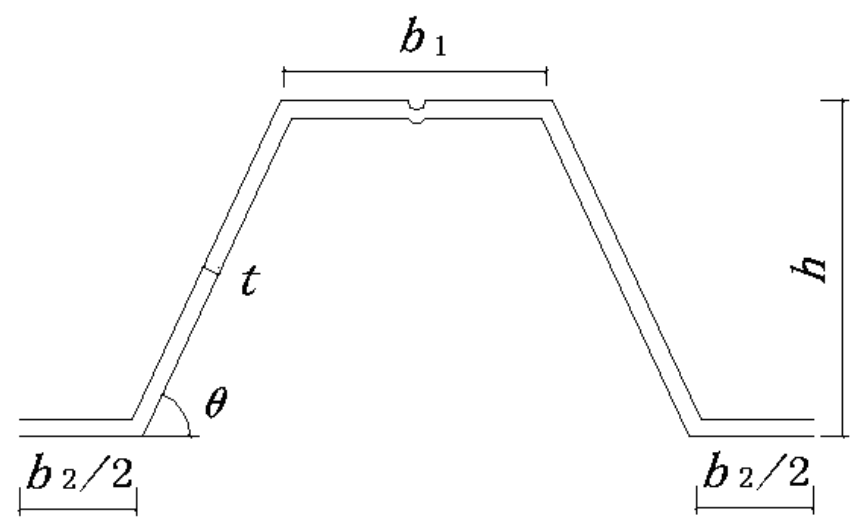

Fig. (2). Cross section of a wave band of profiled steel sheet.

In the transversal loading stage, the stress magnitude of profiled steel sheet is low and the deformation is small without obvious local buckling. In the vertical loading stage, the curve is shown in Fig. (3) which indicates the relationship between the vertical resultant compression $N$ on a wave band of profiled steel sheet and the deformation $y$ out of plane occurring on the node with the maximum deformation out of wall plane. It shows that in the middle loading stage of vertical compression, local buckling occurs on the sheet, and buckling deformation increases rapidly with increasing loads. For the general deformation distribution, the local buckling mainly occurs in the upper region of wall, especially, the local buckles which are close to the left and right boundaries having the maximum deformation when it reaches the vertical ultimate bearing capacity $N_{\text {cr. }}$. When it reaches $N_{\text {cr }}$, plasticity develops 
Table 1. Section parameters of model 1and model 2.

\begin{tabular}{|c|c|c|c|c|c|c|c|}
\hline Model Number & $\boldsymbol{\theta}$ & $\boldsymbol{t} / \mathbf{m m}$ & $\boldsymbol{h} / \mathbf{m m}$ & $\boldsymbol{b}_{\mathbf{1}} / \mathbf{m m}$ & $\boldsymbol{b}_{\mathbf{2}} / \mathbf{m m}$ & Number of Wave Bands & Width of Wall/m \\
\hline \hline Model 1 & $70^{\circ}$ & 3 & 90 & 70 & 300 & 7 & 3.05 \\
\hline Model 2 & $90^{\circ}$ & 3 & 80 & 50 & 170 & 13 & 2.86 \\
\hline
\end{tabular}

obviously in the aforementioned region. For the deformation distribution on the cross section of sheet, local buckling occurs mainly on the web as the web is high and its flakiness ratio is comparatively large. The web is apt to locally buckle because of compressed stress and shear stress action. The compressed flange of sheet is not sensitive to local buckling since its width is comparatively small. For all the analyzed profiled steel sheet computation models, neither obvious overall flexural buckling nor flexural-torsional buckling out of the bending plane occurs on the wall in the loading process. It can be considered that the profiled steel sheet wall which bears the combined loads of bending and vertical compression fails owing to the elastic-plastic local buckling. The load decreases monotonically after snapping through the limit point, and the deformation continues to increase.

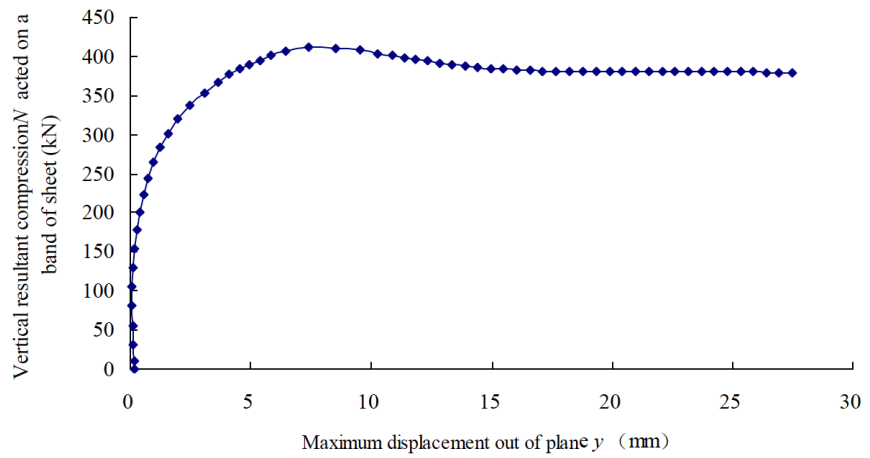

Fig. (3). Relationship curve between vertical compression and deformation out of plane.

\section{INFLUENCES ANALYSES ON PROFILED STEEL SHEET BEARING CAPACITY}

\subsection{Influences of Span and Transversal Load on Bearing Capacity}

Two sets of profiled steel sheets with different cross sections are designed. The section parameters are shown in Table 1. The computation models are established to investigate the influences of sheet span and transversal load $P$ on the vertical bearing capacity. The results are shown in Tables $\mathbf{2}$ and 3. As the flakiness ratio of sheet is large which composes the casing wall, it is apt to local buckle. However, the sheet can bear more loads after local buckling occurs. Consequently, it is necessary to take the post-buckling strength into account. Only for the cold-formed thin-walled steel beam-column, the bearing capacity evaluation formula is produced in current specifications based on the method which only allows effective sections to bear loads. However, there is no relative evaluation formula for profiled steel sheet subjected to both bending and compression. In herein investigation, a wave band of profiled steel sheet is taken as an independent member, and then the vertical load bearing capacity $N_{\text {cro }}$ at a certain transversal load is calculated according to the evaluation formula for cold-formed thin- walled steel beam-column provided in the relevant specification. $N_{\text {cro }}$ is taken as the theoretical solution of vertical bearing capacity for the profiled steel sheet subjected to both bending and compression. The comparison between theoretical solution and finite element solution is conducted to investigate whether the calculation method for coldformed thin-walled steel beam-column is applicable to the profiled steel sheet.

Table 2. Comparison of vertical bearing capacity for model 1 at different sheet spans and different transversal loads.

\begin{tabular}{|c|c|c|c|c|}
\hline \multirow{3}{*}{ Span/m } & $\begin{array}{c}\text { Transversal } \\
\text { Load } P / \mathbf{P a}\end{array}$ & $\boldsymbol{N}_{\text {cr }} / \mathbf{k N}$ & $\boldsymbol{N}_{\text {cro }} / \mathbf{k N}$ & $\boldsymbol{N}_{\text {cr }} / \boldsymbol{N}_{\text {cr0 }}$ \\
\hline \hline \multirow{3}{*}{2.5} & 3500 & 224.12 & 180.06 & 1.245 \\
\cline { 2 - 5 } & 5000 & 206.96 & 163.54 & 1.266 \\
\cline { 2 - 5 } & 7000 & 194.18 & 145.36 & 1.336 \\
\hline \multirow{3}{*}{3} & 3500 & 223.75 & 147.10 & 1.521 \\
\cline { 2 - 5 } & 5000 & 194.55 & 126.16 & 1.542 \\
\cline { 2 - 5 } & 7000 & 184.69 & 92.38 & 1.999 \\
\hline \multirow{3}{*}{3.5} & 3500 & 198.56 & 111.62 & 1.779 \\
\cline { 2 - 5 } & 5000 & 187.61 & 81.75 & 2.295 \\
\hline
\end{tabular}

The results indicate that as the transversal load magnitude $P$ and the wall span $H$ increase, the bending moment increases in which profiled steel sheets are subjected to in the first loading step, and then the remaining vertical compressive bearing capacity reduces. Solutions from finite element method are greater than the theoretical solutions. The reasons maybe that the theoretical solution considers only one wave band of profiled steel sheet as a member which bears loads independently, however, the lateral interaction between every wave band of profiled steel sheet is neglected, which underestimates the load bearing capacity. The ratio of the finite element solution to the theoretical solution increases when the span or the transversal load increases.

\subsection{Influence of Wall Width on Bearing Capacity}

The casing wall with large area in electrostatic precipitator is divided into several blocks by columns. The column spacing determines the wall width. Two sets of models with different sections are designed. The cross section geometrical parameters are shown in Table 4 . When the transversal load magnitude, span and boundary conditions are kept constant, the width of a block of profiled steel sheet wall is varied by adding the number of wave bands so as to investigate the influence of wall width on bearing capacity. The results are shown in Table 5. 
Table 3. Comparison of vertical bearing capacity for model 2 at different sheet spans and different transversal loads.

\begin{tabular}{|c|c|c|c|c|}
\hline \multirow{2}{*}{ Span/m } & Transversal Load $\mathbf{P} / \mathbf{P a}$ & $\boldsymbol{N}_{\text {cr }} / \mathbf{k N}$ & $\boldsymbol{N}_{\text {cro }} / \mathbf{k N}$ & $\boldsymbol{N}_{\text {cr }} / \boldsymbol{N}_{\text {cr0 }}$ \\
\hline \hline \multirow{3}{*}{2.5} & 3500 & 211.47 & 172.14 & 1.228 \\
\cline { 2 - 5 } & 5000 & 208.28 & 156.29 & 1.333 \\
\cline { 2 - 5 } & 7000 & 205.62 & 136.76 & 1.504 \\
\hline \multirow{3}{*}{3} & 3500 & 208.77 & 114.76 & 1.558 \\
\cline { 2 - 5 } & 5000 & 202.16 & 92.87 & 1.762 \\
\cline { 2 - 5 } & 7000 & 197.11 & 2.122 \\
\hline
\end{tabular}

Table 4. Section parameters of model 3 and model 4.

\begin{tabular}{|c|c|c|c|c|c|}
\hline Model Number & $\boldsymbol{\theta}$ & $\boldsymbol{t} / \mathbf{m m}$ & $\boldsymbol{h} / \mathbf{m m}$ & $\boldsymbol{b}_{\mathbf{1}} / \mathbf{m m}$ & $\boldsymbol{b}_{\mathbf{2}} / \mathbf{m m}$ \\
\hline \hline Model 3 & $45^{\circ}$ & 3 & 200 & 100 & 200 \\
\hline Model 4 & $60^{\circ}$ & 3 & 100 & 100 & 100 \\
\hline
\end{tabular}

The results indicate that the vertical load bearing capacity of the sheet with tensioned edge flanges being constrained is greater than that of the sheet with compressed edge flanges being constrained. From the aforementioned analyses, it can be observed that at the ultimate loads, the significant stresses and deformations occur in the marginal region of wall near

Table 5. Comparison of vertical bearing capacities for model 3 and model 4 at different sheet width.

\begin{tabular}{|c|c|c|c|c|c|c|c|}
\hline Model Number & $\begin{array}{c}\text { Number of } \\
\text { Wave Bands }\end{array}$ & Width/m & Span/m & $\begin{array}{c}\text { Transversal } \\
\text { Load } P / P a\end{array}$ & $N_{\mathrm{cr}} / \mathbf{k} \mathbf{N}$ & $N_{\mathrm{cr} 0} / \mathrm{kN}$ & $N_{\mathrm{cr}} / N_{\mathrm{cr} 0}$ \\
\hline \multirow{3}{*}{ Model 3} & 3 & 2.1 & \multirow{3}{*}{2.5} & \multirow{3}{*}{3500} & 390.42 & \multirow{3}{*}{335.19} & 1.165 \\
\hline & 4 & 2.8 & & & 356.23 & & 1.063 \\
\hline & 5 & 3.5 & & & 350.60 & & 1.046 \\
\hline \multirow{3}{*}{ Model 4} & 7 & 2.2 & \multirow{3}{*}{2.5} & \multirow{3}{*}{5000} & 248.57 & \multirow{3}{*}{185.05} & 1.433 \\
\hline & 9 & 2.8 & & & 243.74 & & 1.406 \\
\hline & 11 & 3.5 & & & 241.33 & & 1.392 \\
\hline
\end{tabular}

The results indicate that the vertical compression bearing capacity of a single wave band of profiled steel sheet reduces as the wall width increases. The reasons are analyzed as due to the increment in wave bands number and wall width, the middle band of profiled steel sheet departs from the boundary constraints, which weakens the interaction between each wave band of profiled steel sheet. The deformation control on sheet is weakened and the stability of wall is deteriorated. Consequently, the vertical compressive bearing capacity decreases. With the increasing wall width, the ratio of finite element solution to the theoretical solution decreases.

\subsection{Influence of Boundary Conditions on Bearing Capacity}

Both the vertical edges of wall in aforementioned analyzed models are tensioned under transversal loads. Thus, both the edge tensioned flanges of profiled steel sheet are constrained. In order to investigate the influence of varying boundary conditions on bearing capacity of profiled steel sheet wall subjected to both bending moment and compression, comparisons are conducted between walls with edge tensioned flanges being constrained and walls with edge compressed flanges being constrained. The parameters of cross sections for different models are shown in Table 6 and the computation results are shown in Table 7.
Table 6. Section parameters of model 5 and model 6.

\begin{tabular}{|c|c|c|c|c|c|}
\hline Model Number & $\boldsymbol{\theta}$ & $\boldsymbol{t} / \mathbf{m m}$ & $\boldsymbol{h} / \mathbf{m m}$ & $\boldsymbol{b}_{\mathbf{1}} / \mathbf{m m}$ & $\boldsymbol{b}_{\mathbf{2}} / \mathbf{m m}$ \\
\hline \hline Model 5 & $45^{\circ}$ & 3 & 200 & 100 & 200 \\
\hline Model 6 & $60^{\circ}$ & 3 & 100 & 100 & 100 \\
\hline
\end{tabular}

the boundary constraints. In the transversal loading stage, if the compressed edge flanges are connected with the columns, the region of sheet near the boundary constraints is subjected to transversal compressive stresses and buckles emerge. However, if the tensioned edge flanges are connected with the columns, they are subjected to tensile stresses without buckling. The prior transversal compressive stresses and local buckling accelerate the local buckling of marginal region in the vertical loading stage and gradually reduce the effective cross section of sheet. As the final failure usually originates from the elasto-plastic local buckling occurring in the marginal region near boundary constraints, the load bearing capacity of sheet is impaired. Consequently, the load bearing capacity of sheet with tensioned flanges being constrained is greater than that of sheet with compressed flanges being constrained. When the compressed flanges are constrained, in some cases, the 
Table 7. Comparison of load bearing capacities for model 5 and model 6 in different boundary conditions.

\begin{tabular}{|c|c|c|c|c|c|}
\hline Model Number & Boundary Condition & Transversal Load $P / P a$ & $N_{\mathrm{cr}} / \mathbf{k N}$ & $N_{\text {cro }} / \mathbf{k N}$ & $N_{\text {cr }} / N_{\text {cr0 }}$ \\
\hline \multirow{6}{*}{ Model 5} & \multirow{3}{*}{ tensioned edge flanges being constrained } & 3500 & 366.23 & 335.19 & 1.093 \\
\hline & & 5000 & 356.23 & 325.41 & 1.095 \\
\hline & & 7000 & 347.10 & 314.07 & 1.105 \\
\hline & \multirow{3}{*}{$\begin{array}{l}\text { compressed edge flanges being } \\
\text { constrained }\end{array}$} & 3500 & 316.41 & 335.19 & 0.944 \\
\hline & & 5000 & 314.68 & 325.41 & 0.967 \\
\hline & & 7000 & 312.34 & 314.07 & 1.014 \\
\hline \multirow{6}{*}{ Model 6} & \multirow{3}{*}{ tensioned edge flanges being constrained } & 3500 & 247.96 & 185.05 & 1.340 \\
\hline & & 5000 & 243.74 & 173.41 & 1.406 \\
\hline & & 7000 & 241.63 & 158.59 & 1.524 \\
\hline & \multirow{3}{*}{$\begin{array}{l}\text { compressed edge flanges being } \\
\text { constrained }\end{array}$} & 3500 & 235.29 & 185.05 & 1.273 \\
\hline & & 5000 & 230.47 & 173.41 & 1.329 \\
\hline & & 7000 & 217.80 & 158.59 & 1.373 \\
\hline
\end{tabular}

theoretical solutions are a little greater than the finite element solutions.

\section{CONCLUSION}

By the nonlinear finite element method, computing models are established according to geometric sizes of profiled steel sheet wall usually used in practical electrostatic precipitators, and then investigations are conducted for determining the vertical compression bearing capacity of wall after a certain transversal load is applied. The conclusions are obtained as follows:

(1) For the profiled steel sheet walls analyzed herein, all the failures present the elastic-plastic local buckling on the marginal region of wall close to columns. The sheet does not turn the overall buckling out of the bending plane. Consequently, the currently applied method in practical engineering is reasonable as only the stability of sheet in the bending plane is taken into account, however, the stability of sheet out of plane is ignored.

When the transversal load or sheet span increases, the bending moment increases, which the profiled steel sheet is subjected to, and then the vertical compressive bearing capacity reduces.

(3) For the profiled steel sheet with a certain cross section, when the number of wave bands increases, the wall width increases, and then the vertical compressive bearing capacity reduces.

In the transversal loading step, flanges at one side of the profiled steel sheet are tensioned and the flanges at the other side are compressed. For the case in which the tensioned flanges are connected with the columns on both sides of the wall, the vertical compressive bearing capacity of profiled steel sheet is greater than for the case in which the compressed flanges are connected with the columns on both sides.

(5) A wave band of profiled steel sheet is taken as an independent member, and then its vertical load bearing capacity after applying a certain transversal load can be calculated according to the stability evaluation formula for beam-column in the bending plane which is provided in the cold-formed thinwalled steel structures specification. The vertical bearing capacities of sheet obtained by specification method are generally slightly smaller than in the solutions from finite element method. Consequently, a wave band of profiled steel sheet can be taken as an independent cold-formed thin-walled steel beamcolumn, and then its bearing capacity obtained according to the relevant formulas in the specification can be regarded as a conservative reference solution for the profiled steel sheet wall subjected to both bending and vertical compression.

\section{CONFLICT OF INTEREST}

The authors confirm that this article content has no conflict of interest.

\section{ACKNOWLEDGEMENTS}

This research is financially supported by the National Natural Science Foundation of China (No. 51308258) and the Natural Science Foundation of Jiangsu Province (No. BK20130149).

\section{REFERENCES}

[1] B. Uy, and M. A. Bradford, "Local buckling behaviour of trough girders composed of an assemblage of profiled steel sheets", ThinWalled Structures, vol. 22, pp. 97-120, 1995.

[2] R. M. Lucas, F. G. A. A1-Bermani, and S. Kitipornchai, "Modelling of cold-formed purlin-sheeting systems - Part 1: Full Model", Thin-Walled Structures, vol. 27, pp. 223-243, 1997.

[3] R. M. Lucas, F. G. A. A1-Bermani, and S. Kitipornchai, "Modelling of cold-formed purlin-sheeting systems - Part 2: Simplified Model", Thin-Walled Structures, vol. 27, pp. 263-286, 1997.

[4] A.M. Akhand, W.H. Wan Badaruzzaman, and H.D. Wright, "Combined flexure and web crippling strength of a low-ductility high strength steel decking: experiment and a finite element model", Thin-Walled Structures, vol. 42, pp. 1067-1082, 2004. 
[5] M.M. Alinia, S.A.A. Hosseinzadeh, and H.R. Habashi, "Numerical modelling for buckling analysis of cracked shear panels", ThinWalled Structures, vol. 45, pp. 1058-1067, 2007.

[6] B. Uy, H. D. Wright, and M. A. Bradford, "Combined axial and flexural strength of profiled composite walls", Proceedings of the Institution of Civil Engineers: Structures and Buildings, vol. 146, pp. 129-139, 2001.

[7] S. Rafiei, K.M.A. Hossain, M. Lachemi, K. Behdinan, and M.S. Anwar, "Finite element modeling of double skin profiled composite shear wall system under in-plane loadings", Engineering Structures, vol. 56, pp. 46-57, 2013.

[8] G.P. Mezzomo, I. Iturrioz, G. Grigoletti, and H.M. Gomes, "Influence of the fixing type in the optimization of trapezoidal roofing sheets", Journal of Constructional Steel Research, vol. 96, pp. 26-39, 2014.

[9] Hubei Provincial Development and Planning Commission, P. R. China, Technical code of cold-formed thin-wall steel structures (GB 50018-2002), 2003.

Received: July 25, 2014

Revised: August 4, 2014

Accepted: August 4, 2014

(C) Wang et al.; Licensee Bentham Open.

This is an open access article licensed under the terms of the Creative Commons Attribution Non-Commercial License (http://creativecommons.org/licenses/by-nc/4.0/) which permits unrestricted, non-commercial use, distribution and reproduction in any medium, provided the work is properly cited. 